\title{
STUDY OF WATER ROLE TOWARDS JORDAN VALLEY DEVELOPMENT BY RS AND GIS
}

\author{
O. Dhaimat \\ Civil Engineering Department, Al-Isra UniversityP.O.Box 22, 33 Al-Isra \\ University P.O.Box 11622, Amman-Jordan \\ Email: Oqlahdhaimat@yahoo.com
}

(Received September 18, 2008 Accepted October 9, 2008)

\begin{abstract}
Jordan an example of semi arid region in the Middle East has serious problems that related to the shortage of water resources and agriculture yield which leads to the incremental of desert area of the whole territory. The Jordan valley stills the resource of vegetations and cash crops because of water availability that coming through ghore canal from Yarmouk River.

Remote sensing technique and geographic information system were the tool of collecting, analysis, and output data in short time and real mood. Besides that, science, technology, management, and money are the major parameters that affect the development of present study, if they are applied well by researchers, planners, and decision makers.
\end{abstract}

KEYWORDS: Semi arid, Jordan valley, Ghore canal, RS, GIS, TM, Vegetation, and cash crops.

\section{INTRODUCTION}

Jordan locates in semi arid region in the Middle East where evaporation is so high, vegetation cover is so small, and desert is so wide. This happens due to the shortage of rainfall, less number of streams and other water resources, high ratio of population growth, and development of life standard. These factors create a lot of problems towards daily life of people and other activities of human kind.

Based on that it is necessary to use the available water resources in proper way, and to look here and there for other resources in order to decrease the gap between water demand and resources to reply with the requirements of drinking, domestic, industries, and agriculture uses.

Jordan valley is considered the home land of agriculture in the country; particularly the vegetation and cash crops, due to the role of irrigation ghore canal, which receives its water from Yarmouk River and discharges it within that area. For that it was necessary to use each dunnum in this area for increasing the agricultural land and national fund income.

To obtain accurate data about the command area, it needs to investigate the relation between water, crop, and land in suitable way. Also, it is required to follow certain methods to get the optimum output and use. One of these methods is the remote sensing (RS) technique due to its sophisticated equipments and wide area that detected in one trip. The philosophy of this technique is based on collecting data about the earth without contact with its surface through sensors mounted on the satellite, which 
measure the energy that reflected from the earth surface. This information can be displayed as digital images or photographs. These sensors can be mounted on a satellite or on a plane or other air born structures. Two types of sensors are used; passive and active. The former records reflected radiation during daylight hours that coming initially from solar energy such as thematic mapper (TM) system which mounted on the satellite. The latter generates the energy within the sensor its self like laser beam system which sends a beam of light within known wave length and frequency. This beam hits the earth surface and reflects it back to the sensor.

The popular satellite which designed to monitor the earth surface features is the landsat which used to collect multispectral earth data from satellite platform due to the combination of sensors with spectral bands tailored to earth observation, function spatial, resolution, and aerial coverage.

Most of the common image processing functions can be categorized into four groups including preprocessing, enhancement, transformation, and classification.

The first group involves registration and radiometric correction. Image enhancement is used to make it easier for visual interpretation and understanding of imagery bands of data. Image classification deals with features in an image using the elements of visual interpreted to identify the homogeneous groups of pixels which are matching with various features or land cover classes of interest.

The resultant is to obtain a mosaic of pixels which belongs to particular theme producing thematic map of original image. Figure 1 shows the image classification of study area for 1984, 1994 and 2001.

This data enters Geographic Information System (GIS) which has the ability to classify, analysis and produce acceptable outputs in various shapes including statements, graphs, and maps through sophisticated computers and softwares in order to help the users, planners, and decision makers to find the best methods of solution of these chronic difficulties of water occurrence, convey, distribution and use in this country.

The scope of this paper is to follow previous techniques to show the real situation at Jordan valley and to give guide for selecting proper ways of available water use and their development in the future, especially in agriculture field which becomes facing a number of problems due to the shortage of water and bad application of watersoil-crop relationship.

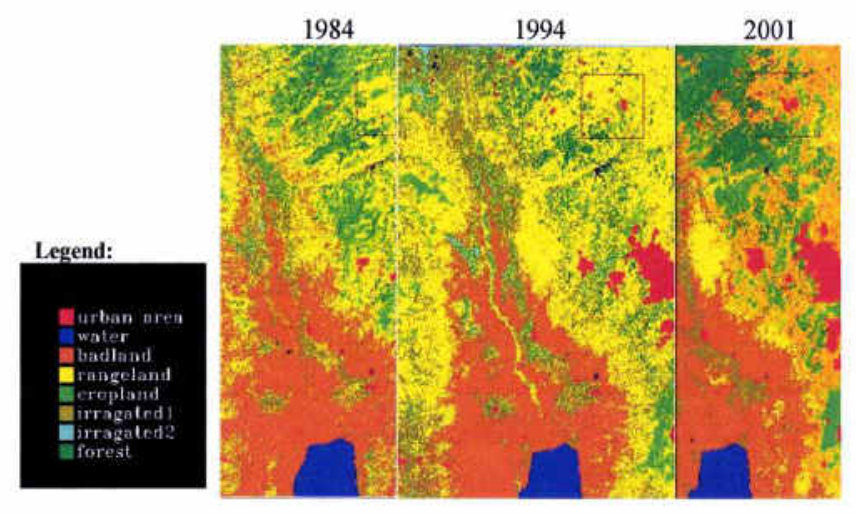

Fig.1 Classification of 1984, 1994, and 2001 images of study area 


\section{DESCRIPTION OF STUDY AREA}

As shown in Fig.2, Jordan valley is located at the west part of the country at north side of the Dead Sea within area around $1600 \mathrm{~km}^{2}$ approximately. The features of the area are hills, plains, and water courses.

The annual rainfall is ranged from $50 \mathrm{~mm}$ at west part to $400 \mathrm{~mm}$ at east side of the study area. The soil of the area belongs to the yellow type of Mideterian soil group and most of the geological formations are limestone. This leads to look carefully for water resources during the various seasons of the year in order to obtain required yield of the cash crop. ${ }^{(2,3)}$

\section{DATA COLLECTION AND METHODOLOGY}

The collected data of the study area was obtained by landsat satellite image 5 (TM) for 1984, 1989, 1994, and 2001. Also topographic maps scale 1:50000 were used as another resource of data.

Most of the common image processing functions can be categorized into preprocessing, enhancement, transformation, and classification. Preprocessing involves geometric registration to identify the image coordinates of group of control points in images and matching them with their true positions in ground coordinates which are measured from maps.

Enhancement is used to make image easy for visual interpretation and understanding. Transformation involves the manipulation of multiple bands of data. Classification means that features in an image are based on elements of visual identification of homogenous groups of pixels that represent various features or land cover classes of interest. In addition to that, digital image classification uses the spectral information represented by digital numbers in one or more spectral bands.

This type of classification is termed as spectral recognition. Common classification procedures can be broken down into broad subdivisions based on the method used; supervised and unsupervised classification. In a supervised classification the analyst identifies the imaginary homogenous samples of the different surface cover types of interest.

Unsupervised reverses the previous one, where spectral classes are grouped first based on the numerical information in the data. ${ }^{(1,2,3)}$

Land cover and land use are often interchangeable, but their actual meanings are quite distinct. Land cover refers to the surface cover of the ground such as vegetation, urban infrastructure, water, and bare soil. Land use refers to the purpose of land service like recreation, wildlife, and agriculture. Land cover use studies are multidisciplinary in nature and thus the participants involved in such work are numerous and varied, ranging from international wildlife and conservation foundation to government researchers and forestry companies. Regional government agencies have an operational need for land cover inventory and land use monitoring.

In addition to facilitating sustainable management of the land, land cover use information may be used for planning, monitoring, and evaluation of development, industrial activity or soil reclamation. Detection of long term changes in land cover may reveal a response to a shift in local or regional climatic conditions, Therefore, land information which ranging from cartographic to thematic processes is used by number 
of departments such as natural resource agencies, environmental researchers, conservation authorities, and municipal affairs.

Normally, vegetation index can be obtained by remote sensing devices which operate in the green, red, and near infra-red region of the electromagnetic spectrum. Therefore, they can discriminate radiation absorption and reflectance.

Also, they trace the influence of green leafy material on incoming and reflecting radiation.

Soil moisture as an indicator of determination of crop yield potential should be refer to the water content in the upper layer of soil that is necessary for plant growth in one hand and allow vapor to rise into the atmosphere in the other hand. Based on that, early detection will help avoiding dry conditions that leads to the crop damage or potential drought, which is in turn can serve to warn farmers, prepare humanitarian aid to risk areas, or give international commodities towards a competitive advantage.

Beside that, it serves as warning for subsequent flooding when the soil becomes too saturated, so no chance for holding any further runoff or precipitation.

Soil moisture content is an important parameter in watershed modeling that provides information on hydroelectric and irrigation capacity, where it predicts amount of runoff evaporation rates and soil erosion in areas of active deforestation. ${ }^{(4,5)}$

Besides that, Tassled Cap formula was used to transform Landsat MSS or Landsat TM into number of layers, where the former transforms original data into soil brightness index (SBI), green vegetation index (GVI), yellow stuff index (YSI), and non such index (NSI). But, with reference to the latter, vegetation index consists of three factors; brightness, greenness, and other. The first two are equivalent to SBI and GVI in MSS, while third one is related to soil features. The major uses of this information are agricultural marketing, includes commodity brokers, large scale farming managers, conservation authorities, and hydroelectric power producers.

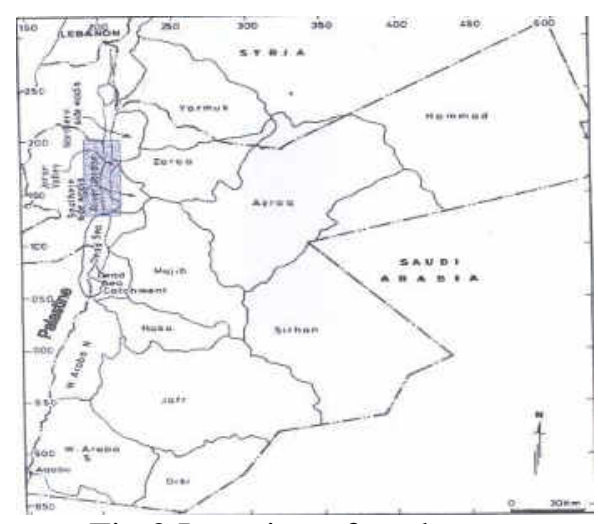

Fig.2 Location of study area

\section{ANALYSIS}

Generally, Study of various changes of the specific area or its development needs updating the variation of land cover, land use, and natural resources management, particularly water resources, methods of collecting data about these parameters include maps, aerial photographs, satellite images, and field works. 
Out of the previous methods, remote sensing was the scope of this paper due to its quick ability of data collection and detection through methodology of sophisticated equipments involving hardware and software tools. Besides that, its capability of cooperation with geographic information system consolidates the procedure of data input, analysis, and output through a number of layers in proper way and short time. Fig 3 represents the image of study area classification of satellite data of study area image containing urban area, badland, water range land and agricultural area.

Based on that, spatial and spectral features as well as temporal features are important factors in these system characteristics. But, spatial and spectral information can be seen from images directly, while temporal features can be seen by changes of the previous ones.

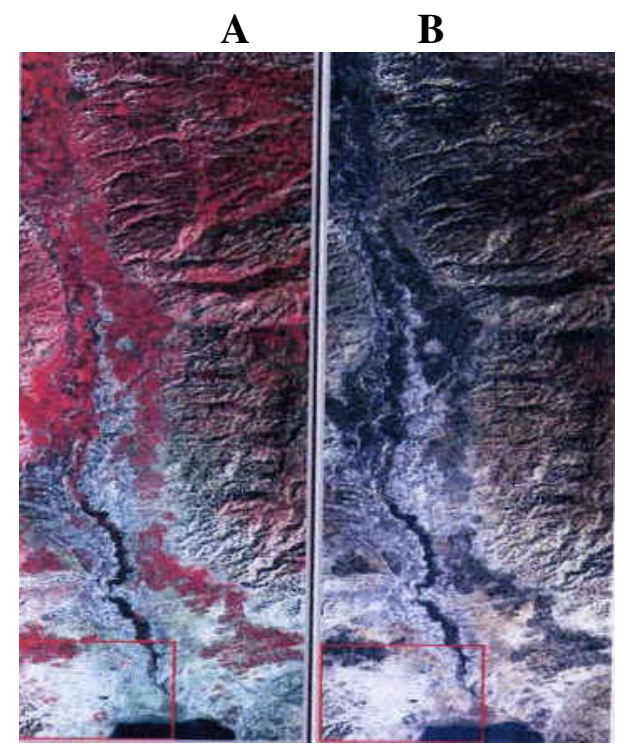

Fig.3 Comparison of Image of study area

Digital images were manipulated by arithmetic process, then landsat images can be used to show the changes between two images that have been taken many years apart, then we subtract the digital image at time one from that at time two to find the difference between them to establish the change detection technique. Such image differencing as a result of that is one of the simplest and most reliable method in remote sensing. But, it needs certain conditions before attempting change detection such as that image must show the same season when vegetation conditions are relatively stable,all images must be accurately matched up to the ground and to other parameters, but cloud affected areas must be removed from analysis.

Also, all images should be radiometrically calibrated to minimize the effects of variation in sensing instruments performance and atmospheric haze between the dates. When these conditions are met, different images can be revealed to express the significant changes of surface phenomena like vegetation, water, and land use. Fig.4 shows the image change between 1989 and 2001.

This difference between two images was based on the fact that the brightness variation between two corresponding pixels of two images tend to form a bell shaped 
distribution, where $80 \%$ of area under curve has minor changes from time one to time two, while the outer portions represents significant changes on both sides. The right side shows increasing loss of vegetation and the left side indicates increase of vegetation gain. Fig.5 expresses that variation between two period gain and loss.

Besides that, the multispectral, TM, senses acquired in previous dates were registered to common data base, then remote sensing of less than 0.3 pixels is tolerated to ensure that high geometry accuracy was achieved.

In addition to that, change detection was carried out based on the analysis of the various layers which were produced from the different resources including area classification, vegetation index, and soil moisture.

Further more, changes of irrigated areas during years 1984-2001 were dictated graphically by using computer program Arc Info, version 9 and the resultant was shown in Fig.6.In this figure, the white color was seen in different years, red color was shown in 1984, green color was only in 1989, blue one was in 2001, yellow in 19841989, cyan in 1989-2001, and magenta in 1984-2001.

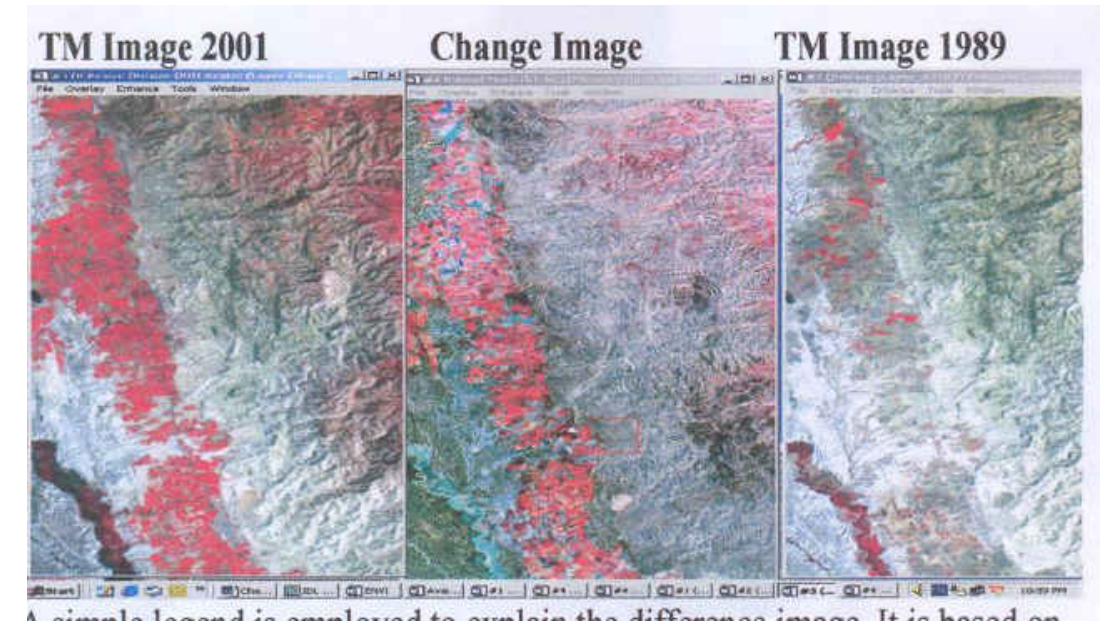

Fig.4 image change between 1989 and 2001

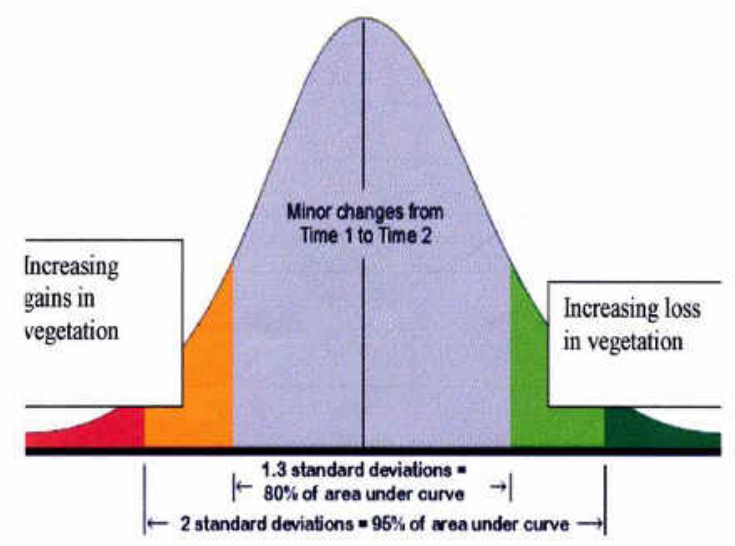

Fig.5 Variation between gain and loss of vegetation 


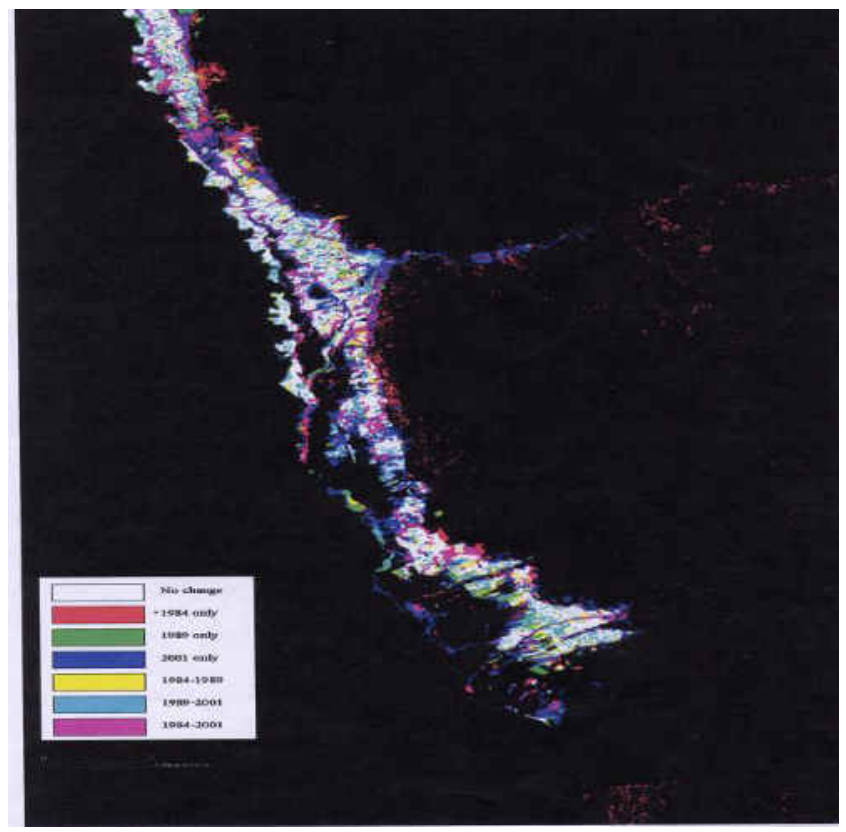

Fig.6 Image of irrigated areas changes during 1984-2001

\section{CONCLUSIONS AND RECOMMENDATIONS}

As mention previously, Jordan locates in semi arid region which needs a lot of efforts to keep the crop yield running well in one hand, and make the population happy and satisfied in other hand.

Jordan valley plays a major role of agriculture and economy in the country, but it depends much on the natural and artificial irrigation in order to get expected goals, which needs continuous research for finding new water resources to reply with the incremental required vegetation lands.

Science is an important factor to study the various parameters that affected the development of Jordan valley in proper way; including water, soil and crop.

Technology becomes addition factor in order to response with the needs of solving problems that stand against safe, quick and suitable procedures.

RS and GIS consider the require tools of technology in this manner to help the planners, managers and decision makers to use, supervise, and follow up the variation of conditions of rainfall and soil use among years.

Furthermore, experience, fund, and equipments are necessary for use, managing, development of available land and resources, and seeking properly for new ones to match with the continuous needs of water and crop.

Finally, cooperation and coordination are required between different departments and institutes of water, soil, and management fields in order to find suitable plans of getting maximum yield and soil use nowadays and in the future. 


\section{REFERENCES}

1. H. Ebna, C.Heipke and K. Eder, 1994 "Spatial information from digital photogrammetry and computer vision", ISPRS symposium, Munich.

2. Harza over seas engineering company, 1979 " Jordan valley irrigation project ", stage II, Jordan valley Authority, project over view, Chicago.

3. Hazleton, 1974 Jordan "The impact of the east ghore and project on land consolidation, distribution and tenure", Royal Scientific Society, Amman, Jordan.

4. Silva, E.A, Mascarenhas, N.D. "Morphological Edge Detectors performance evaluation", proceeding of symposium on cartographic and data base, Maio de 1990, TSU Kuba, Japan.

5. M.C.J Davmen, 1986 "Remote sensing for resources development and environmental management", ITC, Netherland.

6. Menenti, 1984 "Physical aspects and determination of evaporation in deserts, applying remote sensing techniques", phD thesis, wageningen agricultural university, wageningen, Netherland.

\section{دراسة مصادر المياه في وادي الأردن باستخذام أنظمة الاستثعار عن بعد وأنظمة

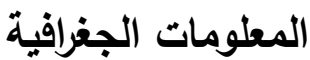

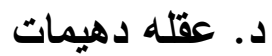

يعتبر الماء مادة حيوية للجنس البشري والمخلوقات الأخرى من اجل نموها وبقائها ونشاطاتها المختلفة

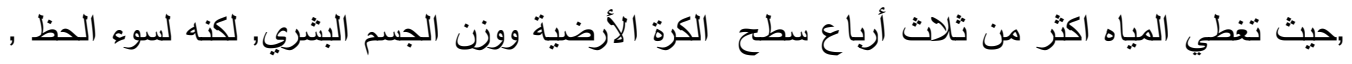

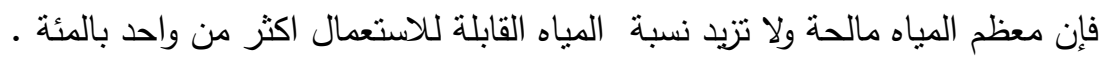

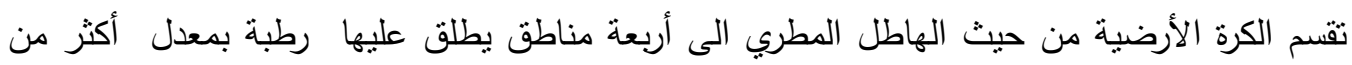

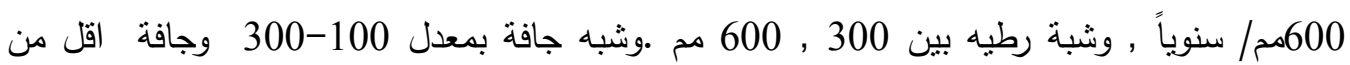
• 100 يقع الأردن في منطقة شبه جافة , حيث بواجه سنة بعد أخرى نقصاً في الهاطل المطري ومصادر المياه السطحية والجوفية مما دفع العاملين في القطاعين العام والخاص للبحث عن مصادئه بعادر مائية تغطي الزيادة السكانية والطلب المتتامي للمياه .

تعتبر السدود منشآت مفضلة لجمع المياه السطحية وشحن المياه الجوفية ,لكنها تحتاج الى مزيد من الدراسات واستخدام احدث المعدات والتكنولوجيا الحديثة لاختيار مواقعها وبنائها ومثال على ذلى ذلك

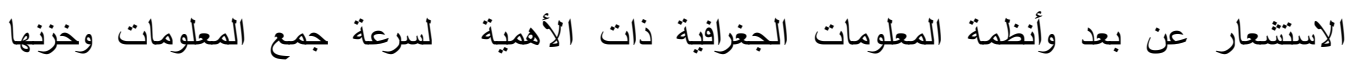

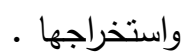

تم اختيار سد الوالا في الأردن نموذجاً لتطبيق تلك المعايير بطريقة مناسبة تناعد الباحثين

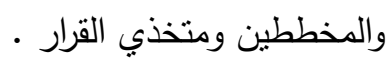

